\title{
Dynamic perspectives on technology transfer: introduction to the special section
}

\author{
David Barberá-Tomás ${ }^{1} \cdot$ Joaquín M. Azagra-Caro ${ }^{1}$ (D) Pablo D’Este ${ }^{1}$
}

Accepted: 1 October 2021 / Published online: 16 October 2021

(c) The Author(s) 2021

\begin{abstract}
Theoretical frameworks acknowledge the dynamic and evolving nature of technology transfer. However, there is a scarcity of empirical work in the field incorporating a dynamic and longitudinal perspective. Several literature reviews call for technology transfer research agendas to include longitudinal studies. In response to such calls, this special section comprises selected contributions to the 2018 Technology Transfer Society (T2S) Conference which address this gap from different angles. The three qualitative and three quantitative works chosen contain research questions and methodologies related to dynamic aspects of technology transfer. We argue that historical and processual studies offer additional new directions.
\end{abstract}

Keywords Technology transfer · University-industry interaction · Longitudinal studies · Time $\cdot$ Evolution

JEL Classification $\mathrm{O} 32 \cdot \mathrm{O} 33 \cdot \mathrm{O} 36$

\section{Introduction}

This special section includes some of the papers presented at the 2018 Technology Transfer Society (T2S) Conference. The conference's main themes revolved around the evolution and dynamics of technology transfer. We proposed this topic because of the gap we identified regarding specific aspects of the dynamics of technology transfer underscored in some of our recent work (Azagra-Caro et al., 2017, 2019). We were interested in whether these gaps highlighted the absence more broadly of longitudinal perspectives in empirical works in this area.

The role played by time in technology transfer would seem clear. Most overarching conceptual approaches in the field of innovation studies stress the importance of the evolution and changing dynamics among innovation actors in general, and among their interactions in particular: from a national systems of innovation (Nelson, 1993; Lundvall, 2010), Mode 2 knowledge production (Nowotny et al., 1994), triple helix model of innovation

Joaquín M. Azagra-Caro

jazagra@ingenio.upv.es

1 INGENIO (CSIC-Universitat Politècnica de València), Camino de Vera s/n, 46022 Valencia, Spain 
(Leydesdorff \& Etzkowitz, 1996), entrepreneurial university (Clark, 1998), and university third mission (Molas-Gallart et al., 2002) perspectives, to more recent frameworks such as productive interactions (Spaapen \& Van Drooge, 2011), the quintuple helix model (Carayannis et al., 2012), societal impacts of research (Bornmann, 2013; D'Este et al., 2018), responsible research and innovation (Von Schomberg, 2013) and transformative change (Schot \& Steinmueller, 2018). These and other conceptual frameworks permeate most of the papers submitted to the 2018 T2S Conference.

Among the more recent papers which emphasize the scarcity of longitudinal perspectives in empirical works in the technology transfer literature are four reviews: Hmieleski and Powell (2018), Vick and Robertson (2018), Skute et al. (2019), and Perkmann et al. (2021). Hmieleski and Powell (2018) find that only 5\% of the empirical studies surveyed employed a longitudinal design. In the context of quantitative research, the authors emphasize the paucity of research on the trajectories of social capital and network position, the infrequent use of methods such as repeated-measures data collection and experience sampling, and the lack of developments of performance evaluation methods. They point out the need for longitudinal research to specify the link between an event and its outcomes with enough precision to be properly informative for policy. The authors expressed concerns also about the existing qualitative research:

Questions regarding the continuity and change in the motivations of scientists choosing to, or not to, commercialize their research would seem to call for longitudinal data collection and observations of circumstances and meanings that inform such decisions. Several of the studies on motivation in our review did use qualitative methods, yet much work remains to fully understand a wide range of persistent process- and motivation-oriented questions.

(Hmieleski \& Powell, 2018: 69)

Vick and Robertson (2018) focus on studies related to the United Kingdom and found a "major omission" (Vick \& Robertson, 2018: 588) in terms of longitudinal investigations of knowledge transfer, and the changing barriers and sustained links over time in particular. Skute et al. (2019) underline some of the most prominent articles in the field, and propose a three dimensional research agenda which includes the individual, organizational, and institutional levels. Common to all three is the need for longitudinal studies: at individual level, longitudinal studies would identify characteristics and motives which enable wellmanaged technology transfer to achieve significant outcomes over time; at organizational level, longitudinal studies would investigate how knowledge exchanges between organizations evolve (specifically vis-à-vis partner proximity); and, at institutional level, longitudinal studies would examine the role played by institutions in the collaboration journey. Perkmann et al. (2021: 9) propose a similar research agenda and call for the development of "longitudinal case studies, based on qualitative or narrative approaches". They suggest this would further research on knowledge transfer activities and their interaction with other academic activities such as teaching.

This special section focuses on these gaps. It contains selected contributions from the 2018 T2S Conference which stand out in terms of their quality and their address of these issues. When considering the submissions in terms of whether the papers were "about time", we adopted a fairly broad perspective which encompassed case studies conducted over prolonged periods, and research based on panel data with several years of observations regardless of whether the corresponding research questions were oriented directly to assessment of changing dynamics. In Sect. 2.1, we highlight how the papers we chose address the issue of dynamics, and discuss how this can be achieved using both qualitative 
and quantitative methods. The selected contributions cover a broad spectrum of phenomena related to technology transfer. Two of the papers (Dolmans et al., 2021; Isaeva et al., 2021) provide analyses of the evolution over time of different university-industry collaboration instruments. The paper by Ye and Crispeels (2021) examines the changes over time in collaboration patterns, and includes collaborations between companies. In contrast, Acosta et al.'s (2021) paper studies the interplay between knowledge spillovers (through disclosure of patent data) and firm competition. Finally, the articles by Giones et al. (2021) and Carayol and Carpentier (2021) address the topic of academic invention from different points of view: respectively, the contribution of students in the search for market applications for academic research, and patented academic inventions in France. Section 2.2 provides an in-depth examination of how these works are linked to the dynamic aspects of technology transfer.

\section{Structure and content of the special section}

\subsection{Summary of the papers}

The six papers in this special section use different approaches to examine the dynamic aspects of the phenomena studied. Dolmans et al.'s (2021) paper analyzes the case of a large European publicly funded initiative aimed at stimulating industry adoption of a technology developed in academia. Their study examines the multiple phases of the project and how researchers learned to transfer their knowledge more effectively during the course of the project. The findings show that the researchers employed concepts from the boundaryspanning literature which studies how individuals translate and frame information, promoting knowledge flow across communities. The results emphasize the mechanism of "perspective taking" for understanding how researchers learn to become boundary-spanners.

The article by Giones et al. (2021) addresses an aspect of technology transfer that is attracting increased interest: the part played by university students in technology transfer activities. The authors analyze an education program which requires students to collaborate with a group of scientists working on different innovation projects to identify market applications for the project outputs. They show that the involvement of students can increase the scientists' interest in and commitment to transferring knowledge in the form of market applications. The longitudinal model proposed by the authors explains how successful transfer of academic knowledge depends on mechanisms such as shared consensus over the technology function and the openness of the scientists to reconsider the meaning of the technology.

Isaeva et al.'s (2021) paper draws on the organizational literature. The authors focus on the case of a new university-industry research center involving 20 companies, designed to promote innovation and long-term research related to reducing greenhouse gas emissions. The study analyzes the center's initial activities and examines whether companies with different (specific or general) goals participate in different coordination activities. They find that firms with specific technological goals engage mainly in structured coordination activities (e.g. annual meetings initiated by the center's management) and that firms with both specific and general research and knowledge development goals rely mainly on unstructured coordination activities (e.g. ad hoc meetings initiated by firm partners).

Ye and Crispeels's (2021) paper contributes to the innovation networks literature. They draw on the notion of trust theory to examine whether direct or indirect collaborations 
foster link strength. The authors distinguish between the two types of collaboration, that is collaborations with partners and collaborations with the partners of partners. They focus on the case of China and identify three periods of time between 1990 and 2016, according to the evolving institutional setting framing network formation. The authors use patent data to show that the effects of collaboration on link strength depend on the type of collaboration (direct or indirect) and institutional developments, from simpler to more complex innovation networks. In general, collaboration fosters link strength but the effect of direct collaborations is stronger compared to the effect of indirect collaborations. The increase in network complexity over time reduces the effects of collaboration on link strength.

Carayol and Carpentier (2021) examine the contribution made by academia to the flow of patented inventions in France over the period 1995 to 2012. They propose a method to identify the amount of academic patenting, that is the number of patents with scientist inventors employed in a university or a research institute, regardless of whether the patent assignee is the individual inventor, a university, or a private sector actor. They investigate the extent and drivers of patenting behavior. They find academic patenting to be more pervasive than expected, and show that some $20 \%$ of scientists working in the hard and life sciences are named as the inventors on at least one patent, and that the propensity for French academics to engage in patenting activity increased over the period examined. The authors also explore the individual and local social drivers of academic patenting and find that professorial status and peer effects have important effects on the increased patenting activity in academia.

The sixth paper is by Acosta et al. (2021) who investigate knowledge flows and technology transfer from the perspective of knowledge spillovers among competing firms. The study examines the extent to which knowledge spillovers affect patent quality among competing firms and the conditions that promote this effect, and focus particularly on competition in a global duopoly-Airbus and Boeing. Knowledge spillovers are assessed based on disclosure of information contained in patents captured by backward citations to competitors. Patent quality is measured based on forward citations to patents. Acosta and colleagues exploit information from patent families owned by Airbus and Boeing during the period 1998 to 2014, and distinguish technological areas based on whether the firms have a dominant position in the production of the technology (i.e. whether they own a significant proportion of the global patents in that technology field). They find that knowledge spillovers affect patent quality only in those technological areas where the focal firms are not dominant.

\subsection{The dynamic approaches adopted by the papers included in this special issue}

\subsubsection{Qualitative research: temporal bracketing, causal loop diagram, and Gioia inductive research}

The three papers that employ qualitative methodologies have some common characteristics. They all study the longitudinal evolution of a phenomenon over time using the tools generally associated with this kind of inquiry, that is interviews, field observation, collection and analysis of secondary data. Two of the papers (Dolmans et al., 2021; Isaeva et al., 2021) focus on a single case; Giones et al. (2021) conduct a comparative study of the evolution of four cases. Dolmans et al. (2021) and Giones et al. (2021) segment their analysis using temporal bracketing, a methodological resource typical of process-focused research in organizational studies, and citing seminal works proposing this dynamic approach 
(Langley, 1999; Langley et al., 2013). This allows them to identify the different stages in the process and the specific mechanisms involved (Tsoukas, 1989). The influence of the process-focused approach is depicted in graphical diagrams representing the dynamic complexity of the process studied (Langley et al., 2013). To complement this processual approach, Dolmans et al. (2021) exploit representation tools provided by the causal loop diagram. This technique was developed in system dynamics research and has been used in management studies to structure key causal mechanisms over time (Van Oorschot et al., 2013). Dolmans et al.'s (2021) and Isaeva et al.'s (2021) papers analyze interview data inductively, grouping them into second-order themes and overarching dimensions based on an initial coding and in line with the method proposed by Gioia and colleagues which has become popular in the field of organizational studies (Gehman et al., 2018; Gioia \& Chittipeddi, 1991; Gioia et al., 2013).

These three papers employ qualitative approaches which are well established in the organizational studies and management fields (Gehman et al., 2018), and apply them to phenomena related to technology transfer in response to calls for qualitative approaches that enable systematic comparison in longitudinal analyses in these disciplines (Cunningham et al., 2017).

\subsubsection{Quantitative research: three alternative methods using patent data for longitudinal analysis of technology transfer}

The three papers employing quantitative methodologies also have some common characteristics. They all study longitudinal aspects of technology transfer and knowledge flows based on a secondary source of information, that is patent data. However, they exploit these data in different ways. Ye and Crispeels's (2021) research question- "What role do former collaborations play in strengthening interorganizational collaborations as the interorganizational collaboration network evolves?" (emphasis added)—links two variables longitudinally. The authors explain the geographical and historical contexts of their research, China from the 1980s to 2020, and distinguish three periods according to the prevailing innovation policy which shaped different institutional and networking scenarios. They estimate the effects of former direct interorganizational collaboration (measured by the number of patents involving two organizations in the previous 5 years) and former indirect interorganizational collaboration (number of joint patents involving the focal partner and its two other collaboration partners in the previous 5 years) on link strength (number of joint patents involving two organizations in the observation year). They test their hypothesis by interacting degree of collaboration with the time period dummies which allows them to analyze the changing effect of degree of collaboration on link strength over time.

Carayol and Carpentier (2021) propose a method to build a longitudinal dataset of academic patenting in all scientific fields at the country level. They match the names of research staff employed in universities and research institutes with the names of patent inventors. This method uses machine learning techniques for the matching and filtering process, and a statistical model to estimate a reliable benchmark to ensure that false positives and false negatives are controlled for and limited. Acosta et al. (2021) use disclosure of information contained in patents to identify and examine the effect of competitors' knowledge as the source of ideas. They study the link over a nearly 20 -year period between firms' acquisition of external knowledge captured by information disclosed by rival companies in their patents, and the focal firms' innovation performance in terms of patent quality. 
They account for different technological competition scenarios to assess the influence of knowledge spillovers on the focal firms' patent quality.

\section{Conclusions}

The embeddedness of technology transfer in socioeconomic systems implies that its scope is influenced by the institutional frameworks: legal and regulatory, political, cultural, etc. These frameworks are constantly evolving and several theoretical approaches in the field of innovation studies discuss how they change and how they affect processes such as technology transfer. However, much empirical work on technology transfer remains static or crosssectional. Despite the declared focus of the T2S Conference 2018 on the dynamics of technology transfer, most of the papers submitted did not comply with this remit. This special section comprises six of the papers presented at the T2S Conference 2018 which do offer concrete ways to incorporate dynamic perspectives in qualitative and quantitative studies of technology transfer-using a variety of approaches which include temporal bracketing, causal loop diagram, and Gioia inductive research, and original uses of patent data to conduct longitudinal analyses of technology transfer.

Ideally, this special section would have included some historical studies. The T2S 2018 call for submissions encouraged historical works and the conference scientific committee incorporated two historians of science and technology. The absence of any historical studies can be interpreted as a sign of the relative disconnect between our communities. We would like to state here that historical studies of technology transfer represent an open field of inquiry whose results are likely to be fruitful. Some of the most influential contributions to the technology transfer literature are historical studies, for example the "grand historical synthesis" which discusses the links between universities and technological advances (Rosenberg \& Nelson, 1994), detailed accounts of early attempts to centralize the commercialization of university research (Mowery \& Sampat, 2001), and studies of the changes to university institutional logics - the norms and priorities which affect the university's mission and technology transfer activities (Feldman \& Desrochers, 2004; Martin, 2003; Martin \& Etzkowitz, 2000). Romero-de-Pablos and Azagra-Caro (2009) and Andersson et al. (2019) are two examples of papers coauthored by a historian of technology transfer and a social scientist working in the innovation studies field. We believe strongly that a dynamic approach to technology transfer should encourage historical studies.

The absence of historical studies among the papers submitted to the conference contrasts with the frequent use of process methods from organizational and management studies. These disciplines traditionally have paid attention to processual approaches (Van de Ven, 1992) to organizational phenomena using qualitative methods which privilege longitudinal case studies. The ontology that is core to these processual approaches is "how and why things-people, organizations, strategies, environments—change, act and evolve over time" (Langley, 2007: 271). That the qualitative articles in this special section explicitly adopt methods based on foundational processual works in organizational studies (Langley, 1999; Langley et al., 2013) is evidence of the influence of processual approaches used in management research. Recent organizational research has made advances in relation to analyzing process phenomena by incorporating the notion of temporality which goes beyond mere sequencing of actions and events across stages of development over time. For instance, Reinecke et al. (2021), Granqvist and Gustafsson (2016), and Reinecke and Ansari $(2015,2017)$ adopt a concept of temporality which is more related to agency, and 
consider that the temporal dimension can be negotiated and socially constructed by certain actors. For example, Granqvist and Gustafsson (2016) study of the creation of a new university in Finland shows that the rapid institutional change (considered exceptional by all the actors involved) required for the constitution of the new university was influenced by the ability of some actors to construct a perception of urgency and irreversibility of change. This notion of the social construction of time horizons could usefully be applied to the issues of interest in the field of technology transfer. The different time horizons that usually drive the activities of academia or industry from the advantages available to technology companies entering a new market to the peer-review processes which govern tenure and academic careers, exemplify the importance of the social construction of different time horizons in the organizations involved in technology transfer processes.

Although the qualitative articles in this special section do not directly address the social construction of the temporality of the processes they study, it is clear that such an approach would serve to deepen some of the findings from these works. For example, Isaeva et al. (2021) show that the coordination required to establish a university-industry research center depended on the time frames (long-term or short-term) of the technology strategies of the companies involved in the center. Given the palpable influence of processual approaches from organizational studies (as demonstrated in this special section), it can be expected that this new approach to temporality will have an impact on future studies of technology transfer.

We hope that the T2S Conference 2018, the works chosen for this special section, the reflection on recent literature reviews, and the plea for historical and processual studies will inspire readers to contribute to technology transfer studies. Analysis of the dynamics of technology transfer, its evolution, and the application of longitudinal research offers a range of opportunities to extend our empirical understanding in the field.

Acknowledgements The editors are grateful to 2018 T2S Conference participants for their comments on the papers published in this special section. We thank the Polytechnic University of Valencia and the Polytechnic Innovation City for their support and hospitality. We are indebted to the reviewers of the papers submitted to this special section. The Spanish Ministry of Science, Innovation, and Universities funded Joaquín M. Azagra-Caro's and Pablo D'Este's contribution to the special section as part of the CSO2016-79045-C2-2-R and the RTI2018-101232-B-100 Projects of the Spanish National R\&D\&I Plan, respectively.

Funding Open Access funding provided thanks to the CRUE-CSIC agreement with Springer Nature.

Open Access This article is licensed under a Creative Commons Attribution 4.0 International License, which permits use, sharing, adaptation, distribution and reproduction in any medium or format, as long as you give appropriate credit to the original author(s) and the source, provide a link to the Creative Commons licence, and indicate if changes were made. The images or other third party material in this article are included in the article's Creative Commons licence, unless indicated otherwise in a credit line to the material. If material is not included in the article's Creative Commons licence and your intended use is not permitted by statutory regulation or exceeds the permitted use, you will need to obtain permission directly from the copyright holder. To view a copy of this licence, visit http://creativecommons.org/licenses/by/4.0/.

\section{References}

Acosta, M., Coronado, D., Ferrándiz, E., \& Jiménez, M. (2021). Effects of knowledge spillovers between competitors on patent quality: What patent citations reveal about a global duopoly. The Journal of Technology Transfer (this issue).

Andersson, D. E., Galaso, P., \& Sáiz, P. (2019). Patent collaboration networks in Sweden and Spain during the Second Industrial Revolution. Industry and Innovation, 26(9), 1075-1102. 
Azagra-Caro, J. M., Barberá-Tomás, D., Edwards-Schachter, M., \& Tur, E. M. (2017). Dynamic interactions between university-industry knowledge transfer channels: A case study of the most highly cited academic patent. Research Policy, 46(2), 463-474.

Azagra-Caro, J. M., Tijssen, R. J., Tur, E. M., \& Yegros-Yegros, A. (2019). University-industry scientific production and the Great Recession. Technological Forecasting and Social Change, 139, 210-220.

Bornmann, L. (2013). What is societal impact of research and how can it be assessed? A literature survey. Journal of the American Society for Information Science and Technology, 64(2), 217-233.

Carayannis, E. G., Barth, T. D., \& Campbell, D. F. (2012). The Quintuple Helix innovation model: Global warming as a challenge and driver for innovation. Journal of Innovation and Entrepreneurship, 1(1), 2.

Carayol, N., \& Carpentier, E. (2021). The spread of academic invention: A nationwide case study on French data (1995-2012). The Journal of Technology Transfer (this issue).

Clark, B. R. (1998). Creating entrepreneurial universities: Organizational pathways of transformation. Issues in higher education. Elsevier.

Cunningham, J. A., Menter, M., \& Young, C. (2017). A review of qualitative case methods trends and themes used in technology transfer research. The Journal of Technology Transfer, 42(4), 923-956.

D’Este, P., Ramos-Vielba, I., Woolley, R., \& Amara, N. (2018). How do researchers generate scientific and societal impacts? Toward an analytical and operational framework. Science and Public Policy, 45(6), $752-763$.

Dolmans, S. A. M., Walrave, B., Read, S., \& van Stijn, N. (2021). Knowledge transfer to industry: How academic researchers learn to become boundary spanners during academic engagement. The Journal of Technology Transfer (this issue).

Feldman, M. P., \& Desrochers, P. (2004). Truth for its own sake: Academic culture and technology transfer at Johns Hopkins University. Minerva, 42(2), 105-126.

Gehman, J., Glaser, V. L., Eisenhardt, K. M., Gioia, D., Langley, A., \& Corley, K. G. (2018). Finding theory-method fit: A comparison of three qualitative approaches to theory building. Journal of Management Inquiry, 27(3), 284-300.

Gioia, D. A., \& Chittipeddi, K. (1991). Sensemaking and sensegiving in strategic change initiation. Strategic Management Journal, 12(6), 433-448.

Gioia, D. A., Corley, K. G., \& Hamilton, A. L. (2013). Seeking qualitative rigor in inductive research: Notes on the Gioia methodology. Organizational Research Methods, 16(1), 15-31.

Giones, F., Kleine, K., \& Tegtmeier, S. (2021). Students as scientists' co-pilots in the onset of technology transfer: A two-way learning process. The Journal of Technology Transfer (this issue).

Granqvist, N., \& Gustafsson, R. (2016). Temporal institutional work. Academy of Management Journal, 59(3), 1009-1035.

Hmieleski, K. M., \& Powell, E. E. (2018). The psychological foundations of university science commercialization: A review of the literature and directions for future research. Academy of Management Perspectives, 32(1), 43-77.

Isaeva, I., Steinmo, M., \& Rasmussen, E. (2021). How firms use coordination activities in university-industry collaboration: Adjusting to or steering a research center? The Journal of Technology Transfer (this issue).

Langley, A. (1999). Strategies for theorizing from process data. Academy of Management Review, 24(4), 691-710.

Langley, A. (2007). Process thinking in strategic organization. Strategic Organization, 5(3), 271-282.

Langley, A., Smallman, C., Tsoukas, H., \& Van de Ven, A. H. (2013). Process studies of change in organization and management: Unveiling temporality, activity, and flow. Academy of Management Journal, 56(1), 1-13.

Leydesdorff, L., \& Etzkowitz, H. (1996). Emergence of a Triple Helix of university—industry—government relations. Science and Public Policy, 23(5), 279-286.

Lundvall, B. A. (Ed.). (2010). National systems of innovation: Toward a theory of innovation and interactive learning (Vol. 2). Anthem press.

Martin, B., \& Etzkowitz, H. (2000). The origin and evolution of the university species. Organisation of mode, 2.

Martin, B. R. (2003). The changing social contract for science and the evolution of the university. Science and innovation: Rethinking the rationales for funding and governance. Edward Elgar, Cheltenham, 7-29.

Molas-Gallart, J., Salter, A., Patel, P., Scott, A., \& Duran, X. (2002). Measuring third stream activities. Final report to the Russell Group of Universities. Brighton: SPRU, University of Sussex.

Mowery, D. C., \& Sampat, B. N. (2001). Patenting and licensing university inventions: Lessons from the history of the research corporation. Industrial and Corporate Change, 10(2), 317-355. 
Nelson, R. R. (Ed.). (1993). National innovation systems: A comparative analysis. Oxford University Press on Demand.

Nowotny, H., Limoges, C., \& Gibbons, M. (1994). The new production of knowledge: The dynamics of science and research in contemporary societies. Sage Publications.

Perkmann, M., Salandra, R., Tartari, V., McKelvey, M., \& Hughes, A. (2021). Academic engagement: A review of the literature 2011-2019. Research Policy, 50(1), 104114.

Reinecke, J., \& Ansari, S. (2015). When times collide: Temporal brokerage at the intersection of markets and developments. Academy of Management Journal, 58(2), 618-648.

Reinecke, J., \& Ansari, S. (2017). Time, temporality and process studies. The Sage Handbook of Process Organization Studies, 402, 416.

Reinecke, J., Suddaby, R., Tsoukas, H., \& Langley, A. (Eds.). (2021). Time, temporality, and history in process organization studies. Oxford University Press.

Romero-De-Pablos, A., \& Azagra-Caro, J. M. (2009). Internationalisation of patents by Public Research Organisations from a historical and an economic perspective. Scientometrics, 79(2), 329-340.

Rosenberg, N., \& Nelson, R. R. (1994). American universities and technical advance in industry. Research Policy, 23(3), 323-348.

Schot, J., \& Steinmueller, W. E. (2018). Three frames for innovation policy: R\&D, systems of innovation and transformative change. Research Policy, 47(9), 1554-1567.

Skute, I., Zalewska-Kurek, K., Hatak, I., \& de Weerd-Nederhof, P. (2019). Mapping the field: A bibliometric analysis of the literature on university-industry collaborations. The Journal of Technology Transfer, 44(3), 916-947.

Spaapen, J., \& Van Drooge, L. (2011). Introducing 'productive interactions' in social impact assessment. Research Evaluation, 20(3), 211-218.

Tsoukas, H. (1989). The validity of idiographic research explanations. Academy of Management Review, 14(4), 551-561.

Van de Ven, A. H. (1992). Suggestions for studying strategy process: A research note. Strategic Management Journal, 13(S1), 169-188.

Van Oorschot, K. E., Akkermans, H., Sengupta, K., \& Van Wassenhove, L. N. (2013). Anatomy of a decision trap in complex new product development projects. Academy of Management Journal, 56(1), 285-307.

Vick, T. E., \& Robertson, M. (2018). A systematic literature review of UK university-industry collaboration for knowledge transfer: A future research agenda. Science and Public Policy, 45(4), 579-590.

Von Schomberg, R. (2013). A vision of responsible research and innovation (pp. 51-74). Responsible innovation: Managing the responsible emergence of science and innovation in society.

Ye, Y., \& Crispeels, T. (2021). The role of former collaborations in strengthening interorganizational links: Evidence from the evolution of the Chinese innovation network. The Journal of Technology Transfer (this issue).

Publisher's Note Springer Nature remains neutral with regard to jurisdictional claims in published maps and institutional affiliations. 